\title{
Molecular Characterization of Bacterial Virulence Factors and the Consequences for Vaccine Design
}

\author{
The 1988 Fleming Lecture \\ By GORDON DOUGAN \\ Department of Molecular Biology, Wellcome Research Laboratories, Langley Court, Beckenham, \\ Kent BR3 3BS, UK
}

(Delivered at the 113th Ordinary Meeting of the Society for General Microbiology, 6th April 1989)

The pathogenesis of bacterial infections involves a complex series of interactions between the pathogenic micro-organisms and the host. The outcome of an infection will depend on a combination of factors including the virulence of the bacterial pathogen, the immune status of the host and the innate resistance of the host. In recent years we have learned to apply molecular techniques to the study of bacterial virulence. Molecular approaches allow us to identify and characterize at a structural, biochemical and immunological level particular bacterial virulence factors. The information we gain from such studies can be used together with in vivo and in vitro models to investigate the immune response to individual bacterial antigens. In the future these studies may lead to the development of novel immunoprophylactic, chemotherapeutic and diagnostic reagents. In this lecture I will present a personalized review of recent molecular studies on bacterial pathogens with particular reference to the potential for vaccine development.

\section{Molecular studies on bacterial virulence determinants}

Arguably one of the most important early projects using genetic approaches to study bacterial virulence was the work of $\mathrm{H}$. Williams Smith and colleagues on the enterotoxigenic Escherichia coli of animals (Smith \& Linggood, 1971). The approaches taken by Smith have served as a model for many subsequent investigations by other workers. Smith used simple genetic crosses to transfer putative virulence determinants including those for haemolysins, enterotoxins and adhesion fimbriae between $E$. coli strains to create isogenic pairs of strains differing in one or other factor. Of great importance was the fact that he used the relevant target host species for his investigations such as pigs or cattle and did not substitute these with less relevant, but more convenient species. His approach was made easier because the genes under study, e.g. K88 or K99 adhesion antigens, the heat-stable (ST) and heat-labile (LT) enterotoxins or haemolysins, were naturally encoded on plasmids. Now we are able to readily transfer naturally chromosomally encoded genes between species using in vitro DNA manipulation supported by classical genetic techniques. Smith's work highlighted the important role of adhesion antigens in promoting colonization of the small intestine by pathogenic bacteria and the role of the enterotoxins in inducing diarrhoea (Smith \& Linggood, 1971).

Probably the first person to apply molecular approaches and gene cloning to the study of bacterial virulence was Stanley Falkow, whose group began cloning the virulence factors characterized so effectively by Smith. Falkow's cloning work on $E$. coli LT and ST played an important role in the subsequent molecular characterization of these important toxins (So et al., 1976, 1978). While in Falkow's laboratory I began a study on the molecular characterization of $E$. coli adhesion antigen determinants. $\mathrm{K} 88$ are the adhesion fimbriae most commonly associated with porcine enterotoxigenic $E$. coli. K88ac was cloned on an $11.5 \mathrm{kbp}$ DNA fragment into the multicopy vector pBR322 (Shipley et al., 1981). Transposon mutagenesis, sub- 
cloning, complementation analysis and E. coli minicells (Dougan \& Kehoe, 1983) were used to map and characterize the polypeptides expressed from the cloned determinant (Kehoe et al., 1981, 1983a; Dougan et al., 1983a, b; Winther et al., 1985). The K88ac determinant was shown to be composed of several closely-linked cistrons encoding the K88 fimbrial structural polypeptide and several polypeptides required for assembly and function of the adhesion fimbriae (Kehoe et al., 1981). The minimal DNA required for functional K88ac expression was around $6 \mathrm{kbp}$ although the natural $\mathrm{K} 88 \mathrm{ac}$ promoter was not encoded on the cloned DNA (Dougan et al., $1983 a, b$ ). This $6 \mathrm{kbp}$ DNA fragment, when returned to wild-type $E$. coli strains, contained sufficient information to allow a non-pathogenic $E$. coli strain to efficiently colonize the small bowel of experimentally infected piglets (Dougan et al., 1986). A variety of adhesion antigen determinants from enterotoxigenic E. coli, e.g. K88ab (Mooi et al., 1979), K99 (Van Embden et al., 1980), F41 (Moseley et al., 1986) and 987P (Morrissey \& Dougan, 1986), have now been cloned and characterized and the genetic organization of these determinants is remarkably similar (Morrissey \& Dougan, 1985; De Graaf, 1988). Indeed, there seems to be a general model organization of fimbrial antigen determinants (Normark et al., 1988).

Adhesion fimbriae play a vital role in the colonization of the mucosal surfaces of the host by bacterial pathogens. Adhesion mediated by such fimbriae involves specific recognition and binding to receptor molecules present on the surface membrane of eukaryotic epithelial cells. This binding to receptor can be inhibited by the presence of specific anti-fimbrial antibody. Thus vaccines have been developed based on purified preparations of adhesion fimbriae (Morgan et al., 1978; B. Nagy et al., 1978; L. K. Nagy et al., 1978). For example, K88-based vaccines have been used in veterinary medicine for a number of years. The identification of adhesins on important pathogens will be vitally important to the development of subunit or acellular vaccines against bacterial infections. Recent work on the adhesins of Vibrio cholerae, the cause of cholera (Mekalanos et al., 1988), and Bordetella pertussis, the cause of whooping cough (Weiss \& Hewlett, 1984), serves to illustrate this.

In addition to adhesion fimbriae, toxins play a vital role in the disease process. We have cloned and characterized several toxin determinants from bacterial pathogens including the $a$-toxin of Staphylococcus aureus (Kehoe et al., 1983b; Fairweather et al., 1983), and the phospholipase $C$ of Pseudomonas aeruginosa (Coleman et al., 1983) and Clostridium perfringens (Leslie et al., 1989). Cloned toxin genes can yield vital information about toxin structure and function and can be used as a start point to create strains harbouring defined mutations in the toxin gene within the natural host (Weiss et al., 1983; Weiss \& Hewlett, 1984; Foster et al., 1988; Black \& Falkow, 1987) or they can serve as the basis for the construction of vaccine strains (Mekalanos et al., 1983; Kaper et al., 1984). Toxin genes can also be readily manipulated to direct the expression of toxoids rather than toxins. An early example of this was the construction of a plasmid that directed the expression of the E. coli LT-B toxoid rather than the active LT toxin (Dallas et al., 1979; Klipstein \& Engert, 1981). More recent work has been undertaken using pertussis toxin (Black et al., 1987; Gross et al., 1989). The work of Neil Fairweather on tetanus toxin serves as an example of the manipulation of a toxin gene to create potentially useful immunogenic toxoids. Tetanus is an extremely potent toxin produced by Clostridium tetani. The current human tetanus vaccine contains semi-purified preparations of tetanus toxoid, inactivated by treatment with formaldehyde. Tetanus toxin is synthesized as a 150000 dalton polypeptide which is normally nicked to generate two polypeptide chains that are linked by disulphide bridges in the active toxin. Papain digestion of the toxin generates a 50000 dalton polypeptide, known as $\mathrm{C}$-fragment, which is derived from the carboxyl end of the toxin. This fragment has been shown to be non-toxic, highly immunogenic and able to protect experimental animals against the lethal effects of toxin. Fairweather and colleagues cloned portions of the tetanus toxin gene in $E$. coli $\mathrm{K} 12$ and derived the entire DNA sequence of the gene (Fairweather et $a l ., 1986 a, b)$. Using $E$. coli expression vectors they were able to construct strains of $E$. coli which expressed portions of the carboxy terminus of the tetanus polypeptide containing portions of the fragment $\mathrm{C}$. These polypeptides were shown to be non-toxic and highly immunogenic in mice. Indeed mice vaccinated with some of these preparations were protected against tetanus toxin challenge (Fairweather et al., 1987). Similar recombinant tetanus polypeptides may 
provide the basis of future tetanus vaccines. Such polypeptides might eventually be synthesized by chemical means.

Although toxoids can be important components of acellular vaccines they may in themselves be insufficient to induce protection against some bacterial pathogens. Bordetella pertussis is the causative agent of whooping cough in young children. The pathogen colonizes the upper respiratory tract by attaching to the ciliated epithelial cells which line the bronchial tubes. The current whooping cough vaccine used in the UK is composed of inactivated whole-cell preparations. There has been an intensive search for an acellular whooping cough vaccine. $B$. pertussis produces an array of surface and extracellular proteins which play a role in virulence. These include pertussis toxin, fimbrial haemagglutinin (FHA), adenylate cyclase, fimbriae and outer-membrane proteins. The expression of these extracellular products is under the control of a central regulatory system called the vir locus, which apparently acts as an environmental sensor that directly regulates gene expresion (Weiss et al., 1983; Weiss \& Hewlett, 1984). Preparations of inactivated pertussis toxin and FHA have recently been tested as an acellular vaccine in Sweden with somewhat inconclusive results. Thus the search is continuing for other candidate antigens for inclusion in new acellular vaccine preparations.

We have been working on a vir-regulated surface-associated protein antigen of $B$. pertussis known as P.69. Pavel Novotny and co-workers originally identified an equivalent protein antigen P.68 on the surface of the related animal pathogen B. bronchiseptica. Preparations of this antigen and monoclonal antibodies against it were able to induce active and passive immunity respectively in experimental animals (Novotny et al., 1985). P.69 of B. pertussis was shown independently to have similar protective properties and to be equivalent to agglutinogen 3 of $B$. pertussis according to the Eldering typing scheme (Brennan et al., 1988). Amino-terminal sequencing of the purified P.69 and peptide fragments derived from it allowed DNA oligonucleotide probes to be synthesized whose sequence corresponded to the amino acid sequences. These probes were used to clone the gene for P.69 from B. pertussis (Charles et al., 1989). Sequences of the gene revealed an open reading frame which encoded a 93478 dalton polypeptide that was apparently processed at the carboxy-terminal end to generate P.69. Examination of the protein sequence revealed two repeated sequences, one rich in glycine and the other rich in proline. These regions may help divide the protein into functioned domains. P.69 and P.93 protein equivalents have now been synthesized at high levels in $E$. coli and other hosts and such proteins are candidates for inclusion in acellular pertussis vaccines.

In concluding this section it is clear that the molecular approach is a powerful way to characterize potential bacterial virulence determinants and it is possible to use the information obtained to aid the development of new subunit vaccines. We can expect this information to eventually help design new chemotherapeutic agents.

\section{The rational attenuation of bacterial pathogens}

We have already discussed one route to the creation of attenuated derivatives of bacterial pathogens. By using modern genetic approaches it is possible to identify key virulence determinants and construct otherwise identical strains which lack the determinant. This approach is well illustrated by the enterotoxin-deficient $V$. cholerae strains. H. Williams Smith and coworkers were able to create attenuated variants of enterotoxigenic $E$. coli by curing them of plasmids. It is clear that if an attenuated strain is to be considered for use as a live vaccine the mode of attenuation should be well defined to aid the quality control of the vaccine. What if a pathogen has few readily definable virulence factors? How might attenuation be readily achieved? One alternative approach is to identify key metabolic pathways whose function is essential for a pathogen to survive in vivo. Of course the importance of such pathways may differ between different pathogens. Let us use Salmonella as an example.

Next to E. coli the Salmonella chromosome is the most completely mapped. In spite of this fact very few so-called virulence genes have been identified, let alone mapped. Lipopolysaccharide (LPS) is known to play an important role in vivo and strains defective in LPS biosynthesis have been used as live vaccines (Wahdan et al., 1982; Levine et al., 1987). However, few other virulence genes have been identified although many Salmonella spp. harbour a virulence- 
associated plasmid which is now being characterized in detail. In the early 1950s Bacon and Burrows isolated auxotrophic mutants of $S$. typhi which were attenuated in mice (Bacon et al., 1950). The attenuated auxotrophs were purine or $p$-aminobenzoic acid (PABA) dependent. Thirty years later Hoiseth \& Stocker (1981) used modern genetics to construct aro $A$ mutants of mouse-virulent $S$. typhimurium strains. aro $A$ is one of several genes encoding enzymes which form the pre-chorismate biosynthetic pathway, the only route by which aromatic compounds can be synthesized by bacteria. aro mutants require PABA, dihydroxybenzoic acid and the three aromatic amino acids for growth. The aro pathway is not present in mammalian cells. When administered to mice aroA mutants of several Salmonella spp. were found to be highly attenuated. Subsequently aro $A$ mutants were shown to be highly effective oral vaccines in several species (Hoiseth \& Stocker, 1981; Stocker et al., 1983; Mukkur et al., 1987; O'Callaghan et al., 1988). aroC (Dougan et al., 1988), aroD (Miller et al., 1989) and strains of Salmonella carrying combinations of aro mutants behave similarly in vivo, and thus vaccine strains harbouring several different aro mutations can be constructed. When administered by the oral route to mice $S$. typhimurium aro mutants can establish a limited infection in the reticuloendothelial system. This infection is cleared after several weeks and the animals remained immune to reinfection (Killar \& Eisenstein, 1985; Maskell et al., 1986, 1987).

$S$. typhimurium strains harbouring purine mutations behaved differently (McFarland \& Stocker, 1987; Nnalue \& Stocker, 1987; O'Callaghan et al., 1988). Strains harbouring mutations before the inosine monophosphate branch point of the purine pathway such as purE are much less attenuated than strains harbouring mutations which act after the branch point, e.g. purA. purA strains are highly attenuated and they are unable to efficiently colonize the reticuloendothelial system following oral infection of mice (O'Callaghan et al., 1988). They are also ineffective oral vaccines. Strains harbouring combinations of aro $A$ and pur $A$ mutations are even more attenuated than purA strains (O'Callaghan et al., 1988). Thus different auxotrophic mutations can give rise to attenuated strains which show major differences in their in vivo behaviour. This is emphasized further if the strains are administered intravenously (i.v.) to mice. aro strains, after an intial drop of about 10 -fold in viable organisms recoverable from liver and spleen in the first $24 \mathrm{~h}$ period, appear to multiply slowly, about a 10 -fold increase over the following 7-14 d, and are then cleared over the following few weeks. Salmonella-susceptible mice. aro strains, after an initial drop of about 10 -fold in viable organisms recoverable from liver immunity against virulent $S$. typhimurium challenge. pur $A$-harbouring strains seem to be more susceptible to killing than aro strains in the first $24 \mathrm{~h}$ but once established the strains persist for several weeks, without any accumulation in numbers of viable organisms. Animals vaccinated with pur $A$ strains can show protection in the early weeks following vaccination but this immunity is not usually long-term and varies according to the Salmonella background strain harbouring the mutation. aro $A$ pur $A$ double mutant strains are very susceptible to killing in the early hours after i.v. inoculation, as much as $99.9 \%$ of the inoculum being cleared. Again aro A purA strains can persist at low levels for long periods of time but the strains do not induce protection against virulent challenge.

In summary, aro $A$ strains are highly effective live vaccines in susceptible animals when administered orally or i.v., whereas pur $A$ and aro $A$ pur $A$ strains are poor vaccines. It is possible to measure key immunological differences in mice receiving aro $A$ vaccines compared to mice receiving $\operatorname{pur} A$ vaccines i.v. in the early days after vaccination. For example, mice receiving aro $A$ vaccines can control a challenge at $14 \mathrm{~d}$ with virulent Listeria monocytogenes whereas mice vaccinated with pur $A$ strains cannot (D. O'Callaghan, unpublished results). Both types of vaccines stimulate the production of anti-Salmonella antibodies. Thus these attenuated variants may prove to be useful for analysing immunity to Salmonella vaccines. There are obviously clear and important differences in the in vivo and immunizing properties of these differently attenuated strains.

Besides using auxotrophic mutations, in what other ways can we indirectly attenuate virulent Salmonella? Curtiss and colleagues recently demonstrated that Salmonella harbouring crp, cya, or crp cya double mutations were attenuated and effective oral vaccines (Curtiss \& Kelly, 1987). The adenylate cyclase system of bacteria is a key regulatory function directly affecting 
expression of a variety of bacterial genes. A number of different interlinked multiple gene regulatory systems or regulons have now been identified in bacteria. Some of these have been associated with the regulation of virulence genes, acting through central regulatory genes which apparently are able to monitor the environment. Examples of such virulence-associated systems include the vir system of $B$. pertussis, the tox-R system of $V$. cholerae (Taylor $e t$ al., 1987) and the accessory regulatory gene associated with extracellular protein production in Staphylococcus aureus (Foster et al., 1988). These interlinked regulatory pathways may be potential targets for creating attenuated strains.

An alternative approach to using previously characterized mutations as a route to attenuation is to introduce random mutations into the genome of a virulent pathogenic bacterium and use screening techniques to identify attenuated variants. This approach is illustrated by the work of Weiss et al. (1983) using Tn5 in B. pertussis and the work of Fields et al. (1986) using Tn10 in Salmonella typhimurium. Weiss \& Falkow (1984) selected strains with altered phenotypes prior to showing loss of virulence whereas Fields et al. used prescreening with an in vitro macrophage killing assay before testing in vivo for attenuation.

Most virulence-associated proteins are likely to be secreted across the cytoplasmic membrane either onto the cell-surface or into the environment. TnphoA is a transposon which can be used to directly select for transposon inserts in genes for secreted proteins (Manoil \& Beckwith, 1985). The use of TnphoA in studying bacterial pathogens has been pioneered by Mekalanos and colleagues (Taylor et al., 1987). TnphoA is a derivative of Tn 5 which has part of the left inverted repeat sequence replaced by the coding region for bacterial alkaline phosphatase, lacking the natural signal sequence. The transposon is engineered in such a way that if TnphoA transposes into a site within the open reading frame a gene fusion can form between the amino-terminal region of the interrupted gene and the transposon-encoded alkaline phosphatase. Alkaline phosphatase is only active when secreted, hence active alkaline phosphatase can only be expressed if TnphoA transposes correctly into the gene for a secreted protein. A simple chromogenic substrate can be used to differentiate between strains producing active compared to inactive alkaline phosphatase. Thus by using a simple plate screening procedure it is possible to enrich for TnphoA insertions into genes for secreted proteins.

Finlay et al. (1988b) employed TnphoA mutagenesis of Salmonella cholerae-suis to generate mutants which were unable to pass through (transcytose) polarized epithelial monolayers of Madin Darby Canine Kidney (MDCK) cells grown on membrane filters. The mutants isolated were unable to invade this cell-line, a property which is associated with the parental strain (Finlay et al., 1988a). The 42 mutants identified were subsequently divided into classes according to the particular phenotypes they displayed. A number of these classes were defective in LPS biosynthesis and were attenuated in their ability to kill mice by the oral route. Some classes were smooth and retained mouse virulence whereas others were smooth but had reduced virulence for the mouse. Thus the ability to invade this particular eukaryotic cell-line did not correlate absolutely with in vivo virulence in the mouse. However, it is clear from this work that Salmonella strains possess surface-associated structures which promote invasion and transcytosis of eukaryotic cells.

Irene Miller and Carlos Hormaeche in collaboration with our laboratory isolated a series of TnphoA mutants of $S$. typhimurium and screened them directly for their ability to kill mice following oral infection (unpublished work). Out of 96 mutants screened, 15 were attenuated and nine of these showed defects in LPS biosynthesis. The six remaining attenuated isolates were smooth. Southern blotting was used to show that the transposon inserts in these mutants mapped to at least five different sites on the Salmonella chromosome. Further, the strains differed in their abilities to establish limited infections in the reticuloendothelial system of mice, suggesting that they harboured mutations affecting different stages in pathogenesis. From these and other studies it is clear that $\operatorname{Tn} p h o A$ and similar reporter transposons will prove to be invaluable tools for studying bacterial virulence.

aro mutations are an effective means of attenuating virulent Salmonella strains. Can the same approach be applied to other bacteria? The aroA gene of $E$. coli encodes the enzyme 5-enolpyruvylshikimate 3-phosphate synthase (Duncan \& Coggins, 1986; Maskell et al., 1988). 
This enzyme is highly conserved in bacteria, lower eukaryotes (Charles et al., 1986) and even plants (Mousdale \& Coggins, 1986). We have cloned and sequenced the aroA gene from Yersinia enterocolitica (P. O'Gaora and others, unpublished) and from B. pertussis (Maskell et al., 1988). The cloned genes were used to construct $Y$. enterocolitica and $B$. pertussis aro $A$ mutants by in vitro mutagenesis in $E$. coli followed by allelic exchange in the original pathogens. Both $Y$. enterocolitica ( $\mathrm{F}$. Bowe and others, unpublished) and $B$. pertussis (M. Roberts and others, unpublished) aro $A$ mutants were attenuated in mouse model systems. Thus it appears that aro mutations may be a simple means of attenuating a range of pathogenic micro-organisms. Such mutants might prove to be invaluable tools for studying infection and immunity.

\section{Live bacteria as carriers of heterologous antigens}

The attenuated strains described above are capable of establishing limited infections. Depending on the strain, or the mode of attenuation, a variety of immune responses can be stimulated in the host. Attenuated Salmonella strains are of particular interest since they are capable, following oral feeding of live organisms, of stimulating an array of immune responses in the host, including local secretory antibody production, humoral antibody production and a variety of cellular immune responses (Dougan et al., 1987 a, $b, 1988$ ). Salmonella aro $A$ strains can stimulate strong immunity to virulent Salmonella challenge whereas pur $A$ mutants stimulate only a local response. Since Salmonella is related to $E$. coli, foreign genes expressed in $E$. coli can be shuttled into Salmonella using a variety of techniques. For example, most plasmid origins of replication which function in $E$. coli will also function in Salmonella. DNA can be introduced into non-virulent Salmonella laboratory strains and then shuttled using bacteriophages such as P22 into smooth vaccine strains. A whole array of potentially important antigens from various pathogens have been expressed in E. coli (Winther \& Dougan, 1984). Some of these have now been moved into Salmonella vaccine strains. They include antigens from bacteria (Black et al., 1987; Clements \& El-Morshidy, 1984; Maskell et al., 1986, 1987), viruses (Tite et al., 1988) and parasites (Sadoff et al., 1988).

Salmonellae are able to enter and survive within macrophages and other related cells. This may be one of the reasons why live Salmonella vaccines are such potent immunogens. I will use a few simple examples of the immunogenicity of Salmonella aroA strains expressing selected heterologous antigens. An attractive goal might be to construct a live attenuated oral Salmonella strain which could induce immunity against several enteric infections. As mentioned previously, both enterotoxigenic $E$. coli and $V$. cholerae produce potent heat-labile enterotoxins which play vital roles in inducing diarrhoeal symptoms in their respective disease syndromes. Both toxins are antigenically and structurally related (Clements \& Finkelstein, 1978; Dallas \& Falkow, 1979, 1980). They are composed of an enzymically active A subunit and a non-toxic but highly immunogenic B subunit. As discussed above, recombinant plasmids have been constructed which direct the expression of LT-B or CT-B. LT-B expression plasmids can be readily introduced into Salmonella aroA vaccine strains which express LT-B in a normal manner (Clements et al., 1986; Maskell et al., 1986, 1987). Mice vaccinated with $S$. typhimurium aroA LT-B-producing strains produce an anti-LT-B secretory IgA response along with high levels of anti-LT-B serum antibodies. These antibodies will neutralize heat-labile toxin activity in tissue culture cell-lines (Clements et al., 1986; Maskell et al., 1986, 1987). Further mice vaccinated with these constructs are immune to subsequent challenge with virulent Salmonella. Antitoxin immunity in itself is probably not sufficient to protect against enterotoxigenic $E$. coli or $V$. cholerae even if a strong local immune response is induced, and additional factors may have to be included in effective vaccines. Nevertheless this type of work represents a step towards the development of new enteric multivalent vaccines.

LT-B is secreted by E. coli and S. typhimurium. Do antigens have to be secreted to the surface of Salmonella vaccines in order to stimulate an immune response in the host? The answer is apparently not. $\beta$-Galactosidase can serve as a model internal non-secreted antigen. $S$. typhimurium is normally a lactose-negative organism and does not produce $\beta$-galactosidase. The functional $E$. coli gene for $\beta$-galactosidase can be introduced into $S$. typhimurium aro $A$ vaccine strains and $\beta$-galactosidase-producing Salmonella can be used to vaccinate mice. Mice 
receiving these live vaccines mount a humoral antibody response to $\beta$-galactosidase and also develop a delayed-type hypersensitivity characteristic of a cellular immune response (Brown $e t$ al., 1987). Thus predominantly internal Salmonella-associated antigens can be recognized following exposure to live Salmonella aro vaccines.

LT-B provides an example of carriage of a bacterial antigen. What about antigens which originate from non-bacterial sources? David O'Callaghan and John Tite at Wellcome have carried out work with the nucleoprotein of infuenza virus. Unlike the haemagglutinin, the internal nucleoprotein is highly conserved in terms of sequence and immunogenicity between different isolates of influenza virus. The nucleoprotein is one of the dominant antigens in the cytotoxic T-cell response to influenza virus in mice. Purified nucleoprotein is capable of inducing protective immunity in mice against a lethal challenge with certain virulent influenza viruses (Wraith et al., 1987). The nucleoprotein gene from $\mathrm{A} / \mathrm{NT} / 60 / 68$ influenza virus has been expressed in $E$. coli as a fusion to cro using the inducible $\lambda \mathrm{P}_{\mathrm{R}}$ promoter (I. Jones and others, personal communication). The nucleoprotein gene was introduced into a $S$. typhimurium aro $A$ vaccine strain and a variant was selected which expressed the nucleoprotein constitutively at a high level (Tite et al., 1988). In fact this strain is an ideal source for purifying the antigen. Mice vaccinated orally with the Salmonella-nucleoprotein construct developed good titres of antinucleoprotein antibodies in their serum in the weeks following vaccination. Mice infected subcutaneously developed a cytotoxic T-cell response to the nucleoprotein. This cytotoxic T-cell response was class II MHC gene-product restricted. Further investigations are now ongoing to see if the mice can be protected against a lethal challenge with the virus.

\section{Conclusions}

In this review I have attempted to illustrate, using selected examples, how molecular biology has changed the approaches taken to study bacterial virulence factors. By analysing in detail the virulence determinants of individual pathogens we have been able, in many cases, to piece together the complex way in which highly evolved pathogens interact with their host. This detailed information will in the future aid the development of new therapies against infectious diseases and other human and veterinary illnesses. Bacterial pathogens interact in a very sophisticated manner with eukaryotic cells and by learning more about these processes we can discover new ways of studying the cell biology of higher eukaryotes. In the future, the study of bacterial pathogens will not be reserved for microbiologists but the work will become entangled with many other disciplines. Thus the area looks to have an exciting future.

I would like to thank the many colleagues, friends and collaborators, too numerous to mention individually, who have helped me pursue my interests in research. In particular I would like to thank Stanley Falkow for his brilliance, friendship and guidance, John Arbuthnott for helping make life in Dublin such a pleasure and John Beale for providing a platform at Wellcome upon which to build a young and dedicated research group. Thanks to Tina Silva for typing this review.

\section{REFERENCES}

Bacon, G. A., Burrows, T. W. \& Yates, M. (1950). The effects of biochemical mutations on the virulence of Bacterium typhosa: the virulence of mutants. British Journal of Experimental Pathology 31, 703711.

Black, R. E., Levine, M. J., Clements, M. L., Losonsky, G., Herrington, D., Berman, S. \& Formal, S. B. (1987). Prevention of shigellosis by a Salmonella typhi-Shigella sonnei bivalent vaccine. Journal of Infectious Diseases 155, 1260-1265.

BLACK, W. J. \& FalKow, S. (1987). Construction and characterisation of Bordetella pertussis toxin mutants. Infection and Immunity 55, 2465-2470.
Brennan, J. J., Li, Z. M., Cowell, J. L., Bisher, M. E., Steven, A. C., Novotny, P. \& Manclark, C. R. (1988). Identification of a 69-kilodalton nonfimbrial protein as a serotype 3 agglutinogen of Bordetella pertussis. Infection and Immunity 56, 31893195.

Brown, A., Hormaeche, C. E., Demarco de Hormaeche, R., Winther, M. D., Dougan, G., Maskell, D. J. \& Stocker, B. A. D. (1987). An attenuated aroA $S$. typhimurium vaccine elicits humoral and cellular immunity to cloned beta galactosidase in mice. Journal of Infectious Diseases 155, 86-92. 
Charles, I. G., Keyte, J. W., Brammar, W. J., Smith, M. M. \& Hawkins, A. R. (1986). The isolation and nucleotide sequence of the complex AROM locus of Aspergillus nidulans. Nucleic Acids Research 14, 22012213.

Charles, I., Dougan, G., Pickard, D., Chatfield, S. N., SMith, M., Novotny, P., MorRisSey, P. M. \& FAIRWEATHER, N. F. (1989). Molecular cloning and characterisation of P69, a protective outer membrane protein from Bordetella pertussis. Proceedings of the National Academy of Sciences of the United States of America (in the Press).

Clements, J. D. \& El-Morshidy, S. (1984). Construction of a potential live oral bivalent vaccine for typhoid fever and cholera-Escherichia coli related diarrhoea. Infection and Immunity 46, 564-569.

Clements, J. D. \& Finkelstein, R. A. (1978). Demonstration of shared and unique immunological determinants in enterotoxins from Vibrio cholerae and Escherichia coli. Infection and Immunity 22, 709 713.

Clements, J. D., Lyon, F. L., Lowe, K. L., Farrand, A. L. \& EL-MORSHIDY, S. (1986). Oral immunisation of mice with attenuated Salmonella enteritidis containing a recombinant plasmid which codes for production of the B-subunit of heat-labile enterotoxin of Escherichia coli. Infection and Immunity 53, 685-693.

Coleman, K., Dougan, G. \& Arbuthnott, J. P. (1983). Cloning and expression in Escherichia coli K 12 of the chromosomal haemolysin (phospholipase C) determinant of Pseudomonas aeruginosa. Journal of Bacteriology 153, 909-915.

Curtiss, R., III \& Kelly, S. M. (1987). Salmonella typhimurium deletion mutants lacking adenylate cyclase and cyclic AMP receptor protein are avirulent and immunogenic. Infection and Immunity 55, 3035-3043.

Dallas, W. S. \& Falkow, S. (1978). Characterisation of an Escherichia coli plasmid encoding for synthesis of heat-labile toxin: molecular cloning of the toxin determinant. Infection and Immunity 21, 405-411.

Dallas, W. S. \& FalKow, S. (1979). The molecular nature of heat-labile enterotoxin (LT) of Escherichia coli. Nature, London 277, 406-407.

Dallas, W. S. \& Falkow, S. (1980). Amino acid sequence homology between cholera toxin and Escherichia coli heat-labile enterotoxin. Nature, London 288, 499-501.

Dallas, W. S., Gill, D. M. \& Falkow, S. (1979). Cistrons encoding Escherichia coli heat-labile toxin. Journal of Bacteriology 139, 850-858.

DE GraAF, F. K. (1988). Fimbrial structures of enterotoxigenic E. coli. Antonie van Leeuwenhoek 54, 395-404.

Dougan, G. \& KeHOE, M. (1983). Use of of minicells in plasmid analysis for 'plasmid technology'. Methods in Microbiology 17, 233-259.

Dougan, G., Dowd, G. \& KeHOE, M. (1983a). Organisation of $\mathrm{K} 88 \mathrm{ac}$-encoded polypeptides in the Escherichia coli cell envelope: use of minicells and membrane protein mutants for studying assembly. Journal of Bacteriology 153, 364-370.

Dougan, G., Kehoe, M., Dowd, G., Sellwood, R. \& WINTHER, M. (1983b). Studies on the expression and organisation of the K88ac adherence antigen. Developments in Biological Standardisation 53, 183-187.
Dougan, G., Sellwood, R., Maskell, D., Sweeney, K., Liew, F. Y., Beesley, J. \& Hormaeche, C. (1986). In vivo properties of a cloned K88ac determinant. Infection and Immunity 51, 344-347.

Dougan, G., Hormaeche, C. E. \& Maskell, D. J. (1987a). Live oral Salmonella vaccines: potential use as carriers of heterologous antigens to the immune system. Parasite Immunology 9, 151-160.

Dougan, G., Maskell, D., Pickard, D. \& HormaECHE, C. $(1987 b)$. Isolation of stable aro $A$ mutants of Salmonella typhi Ty2: properties and preliminary characterisation in mice. Molecular and General Genetics 207, 402-405.

Dougan, G., Maskell, D., O'Callaghan, D., ChatFIEld, S., Charles, I. \& HoRmaeche, C. (1988). Oral vaccination. Antonie van Leeuwenhoek 54, 447451.

Duncan, K. \& Coggins, J. R. (1986). The serC-aroA operon of Escherichia coli. Biochemical Journal 234, 49-57.

Fairweather, N. F., Foster, T., Kennedy, S., Kehoe, M. \& Dougan, G. (1983). Expression of a cloned Staphylococcus aureus $\alpha$-haemolysin determinant in Bacillus subtilis and Staphylococcus aureus. Infection and Immunity 41, 1112-1117.

FAirweather, N. F. \& LynEss, V. A. (1986). The complete nucleotide sequence of tetanus toxin. Nucleic Acids Research 14, 7909-7912.

Fairweather, N. F., Foster, T., Kennedy, S., Kehoe, M. \& Dougan, G. (1983). Expression of a cloned Staphylococcus aureus $\alpha$-haemolysin determinant in Bacillus subtilis and Staphylococcus aureus. Infection and Immunity 41, 1112-1117.

Fairweather, N. F., Lyness, V. A., Pickard, D. J., Allen, G. \& Thomson, R. O. (1986). Cloning, nucleotide sequencing and expression of tetanus toxin fragment $\mathrm{C}$ in E. coli. Journal of Bacteriology 165, 21-27.

Fairweather, N. F., Lyness, V. A. \& Maskell, D. J. (1987). Immunisation of mice against tetanus with fragments of tetanus toxin synthesised in Escherichia coli. Infection and Immunity 55, 25412545.

Fields, P. I., Swanson, R. V., Heidaris, C. G. \& HefrRon, F. (1986). Mutants of Salmonella typhimurium that cannot survive within the macrophage are avirulent. Proceedings of the National Academy of Sciences of the United States of America 83, 51895193.

Finlay, B. B., Gumbiner, B. \& Falkow, S. (1988a). Penetration of Salmonella through a polarized MDCK epithelial cell monolayer. Journal of Cell Biology 107, 221-230.

Finlay, B. B., Starnbach, M. N., Francis, C., Stocker, B. A. D., Chatfield, S. N., Dougan, G. \& FALKOW, S. (1988b). Identification and characterisation of TnphoA mutants of Salmonella which are unable to penetrate through a polarised MDCK epithelial cell monolayer. Molecular Microbiology 2 , 757-766.

Foster, T. J., O'Reilly, M., Patel, A. H. \& Bramley, A. J. (1988). Genetic studies of Staphylococcus aureus virulence factors. Antonie van Leeuwenhoek 54, 475482.

Gross, R., ARICO, B. \& RAPPUOLI, R. (1989). Genetics of pertussis toxin. Molecular Microbiology 3, 119124. 
Hoiseth, S. K. \& Stocker, B. A. D. (1981). Aromaticdependent Salmonella typhimurium are non-virulent and effective as live vaccines. Nature, London 291, 238-239.

KAPER, J. B., LockMaN, H., BALdini, M. M. \& LeVINe, M. M. (1984). Recombinant non-toxinogenic Vibrio cholerae strains as attenuated cholera vaccine candidates. Nature, London 308, 655-658.

Kehoe, M., Sellwood, R., Shipley, P.\& Dougan, G. (1981). Genetic analysis of K88-mediated adhesion of enterotoxigenic Escherichia coli. Nature, London 291, 122-127.

Kehoe, M., Winther, M. \& Dougan, G. (1983a). Expression of a cloned K88ac adhesion antigen determinant: identification of a new adhesion cistron and role of a vector-encoded promoter. Journal of Bacteriology 155, 1071-1077.

Kehoe, M., Foster, T., Duncan, J., Fairweather, N. F. \& Dougan, G. (1983b). Cloning, expression and mapping of the Staphylococcus aureus $\alpha$-haemolysin determinant in Escherichia coli $\mathrm{K} 12$. Infection and Immunity 41, 1105-1111.

KILlaR, L. M. \& EISENSTEIN, T. K. (1985). Immunity to Salmonella typhimurium infection in $\mathrm{C} 3 \mathrm{H} / \mathrm{HeJ}$ and $\mathrm{C} 3 \mathrm{H} / \mathrm{HeNCrlBR}$ mice: studies with an aromaticdependent live $S$. typhimurium strain as a vaccine. Infection and Immunity 47, 605-612.

Klipstein, F. A. \& Engert, R. F. (1981). Protective effect of immunisation of rats with holotoxin or $B$ subunit of Escherichia coli heat-labile enterotoxin. Infection and Immunity 31, 144-150.

Leslie, D., Fair weather, N., Pickard, D., Dougan, G. \& KEHOE, M. (1989). Molecular cloning and characterisation of the alpha-toxin determinant of Clostridium perfringens. Molecular Microbiology 3, 383-392.

LeVine, M. M. Ferreccio, C., Black, R. E., GermanIER, R. \& CHILEAN TYPHOID COMMITTEE (1987). Large-scale field trials of Ty21A live oral typhoid vaccine in enteric-coated capsule formulation. Lancet i, 1049-1052.

Manoll, C. \& Beckwith, J. (1985). TnphoA: a transposon probe for protein export signals. Proceedings of the National Academy of Sciences of the United States of America 82, 8129-8133.

Maskell, D., Sweeney, K., Liew, F. Y., Hormaeche, C. \& Dougan, G. (1986). Attenuated Salmonella typhimurium as live oral vaccines and carriers for delivering antigens to the secretory immune system. In Vaccine 86, pp. 213-216. Edited by R. Chanock, R. Lerner \& F. Brown. Cold Spring Harbor, NY: Cold Spring Harbor Laboratory.

Maskell, D. J., Sweeney, K. J., O'Callaghan, D., HormaEche, C., Liew, F. Y. \& Dougan, G. (1987). Salmonella typhimurium aroA mutants as carriers of the Escherichia coli heat-labile enterotoxin B subunit to the murine systemic and secretory immune systems. Microbial Pathogenicity 2, 211-221.

Maskell, D. J., Morrissey, P. \& Dougan, G. (1988). Cloning and nucleotide sequence of the $\operatorname{aro} A$ gene of Bordetella pertussis. Journal of Bacteriology 170 , 2467-2471.

McFarland, W. C. \& Stocker, B. A. D. (1987). Effect of different purine auxotrophic mutations on mouse virulence of a Vi-positive strain of Salmonella dublin and of two strains of Salmonella typhimurium. Microbial Pathogenicity 3, 129-141.
Mekalanos, J. J., Swartz, D. J., Pearson, G. D. N., HARFord, N., GroYNE, F. \& DE WILDE, M. (1983). Cholera toxin genes: nucleotide sequence, deletion analysis and vaccine development. Nature, London 306, 551-556.

Mekalanos, J. J., Peterson, K. M., Finn, T. \& KNAPP, S. (1988). The pathogenesis and immunology of Vibrio cholerae and Bordetella pertussis. Antonie van Leeuwenhoek 54, 379-388.

Miller, I. A., Chatfield, S., Dougan, G., DeSilva, L., Joysey, H. \& Hormaeche, C. H. (1989). Bacteriophage $\mathrm{P} 22$ as a vehicle for transducing gene banks between smooth strains of Salmonella typhimurium: use in identifying a role for aroD in attenuating virulent Salmonella strains. Molecular and General Genetics 215, 312-316.

Mooi, F. R., De Graaf, F. K. \& Van Embden, J. D. A. (1979). Cloning, mapping and expression of the genetic determinant that encodes for the $\mathrm{K} 88 \mathrm{ab}$ antigen. Nucleic Acids Research 6, 849-865.

MORGAN, R. L., ISAACSON, R. E., MOON, H. W., Brinton, C. C. \& To, C. C. (1978). Immunisation of suckling pigs against enterotoxigenic Escherichia coli induced diarrhoeal disease by vaccinating dams with purified 987 and K99 pili: protection correlates with pilus homology of vaccine and challenge. Infection and Immunity 22, 771--777.

Morrissey, P. M. \& Dougan, G. (1985). Molecular studies on virulence factors associated with enterotoxigenic Escherichia coli isolated from domestic animals. Applications to vaccine development. Veterinary Microbiology 10, 241-251.

MoRRISSEY, P. M. \& Dougan, G. (1986). Cloning and characterisation of the $E$. coli $987 \mathrm{P}$ adhesion fimbriae determinant. Gene 43, 79-84.

Moseley, S. L., Dougan, G., Schneider, R. A. \& Moon, H. W. (1986). Cloning of chromosomal DNA encoding the F4l adhesin of enterotoxigenic Escherichia coli: genetic homology between F41 and K88. Journal of Bacteriology 167, 799-804.

Mousdale, D. M. \& Coggins, J. R. (1986). Detection and subcellular localisation of a higher plant chorismate synthase. FEBS Letters 205, 328-332.

Mukkur, T. K. S., MCDowell, G. H., Stocker, B. A. D. \& Lascelles, A. K. (1987). Protection against salmonellosis in mice and sheep by immunisation with aromatic-dependent Salmonella typhimurium. Journal of Medical Microbiology 24, 11-19.

NAGY, B., Moon, H. W., IsaAcson, R. E. \& To, C. C. (1978). Immunisation of suckling pigs against enterotoxigenic Escherichia coli infection by vaccinating dams with purified pili. Infection and Immunity 21, 269-274.

NaGy, L. K., Walker, P. D., Bhogel, B. S. \& MACKENZIE, T. (1978). Evaluation of Escherichia coli vaccines against enteric colibacillosis. Research in Veterinary Science 24, 39-45.

Nnalue, N. A. \& STocker, B. A. D. (1987). Tests of the virulence and live-vaccine efficacy of auxotrophic and galE derivatives of Salmonella cholerae-suis. Infection and Immunity 55, 955-962.

Normark, S., Hultgren, S., Markland, B. I., StromberG, N. \& TENNANT, J. (1988). Biogenesis of pili adhesins associated with urinary tract infectious E. coli. Antonie van Leeuwenhoek 54, 405-410.

Novotny, P., Kobisch, M., Cownley, K., ChubB, A. P. \& Montaraz, J. A. (1985). Evaluation of 
Bordetella bronchiseptica vaccines in specific-pathogen-free piglets with bacterial cell surface antigens in enzyme-linked immunosorbent assay. Infection and Immunity 50, 190-198.

O'Callaghan, D., Maskell, D., Liew, F., Easmon, C. S. F. \& Dougan, G. (1988). Characterisation of aromatic- and purine-dependent Salmonella typhimurium: attenuation, persistence and ability to induce protective immunity in BALB/c mice. Infection and Immunity 56, 419-423.

Sadoff, J. C., BalloU, R. W., Baron, L. S., Majarian, W. R., Brey, R. N., HockMeYer, W. T., Young, J. F., CrYz, J. J., OU, J., Lowell, G. H. \& Chulay, J. D. (1988). Oral Salmonella typhimurium vaccine expressing circumsporozoite protein protects against malaria. Science 240, 236-240.

Shipley, P. L., Dougan, G. \& Falkow, S. (1981). Identification and cloning of the genetic determinant that encodes for the K88ac adherence antigen. Journal of Bacteriology 145, 920-925.

SMITH, H. W. \& LingGood, M. A. (1971). Observations on the pathogenic properties of the K88, Hly and Ent plasmids of Escherichia coli with particular reference to porcine diarrhoea. Journal of Medical Microbiology 5, 243-250.

So, M., Boyer, H. W., Betlach, M. \& Falkow, S. (1976). Molecular cloning of an Escherichia coli plasmid determinant that encodes for the production of heat-stable enterotoxin. Journal of Bacteriology 128, 463-472.

So, M., Dallas, W. S. \& Falkow, S. (1978). Characterisation of an Escherichia coli plasmid encoding determinant that encodes for the synthesis of heat-labile toxin: molecular cloning of the toxin determinant. Infection and Immunity 21, 405-411.

Stocker, B. A. D., Holseth, S. K. \& SMith, B. P. (1983). Aromatic-dependent Salmonella spp. as live vaccines in mice and calves. Development of Biological Standards 53, 47-54.

Taylor, R. K., Miller, V. L., Furlong, D. G. \& MEKalanos, J. J. (1987). Use of pho $A$ gene fusions to identify a pilus colonization factor coordinately regulated with cholera toxin. Proceedings of the National Academy of Sciences of the United States of America 84, 2833-2837.

Tite, J. P., Russell, S. M., Dougan, G., O'Callaghan, D., Jones, I., Brownlee, G. \& LIEW, F. Y. (1988). Antiviral immunity induced by recombinant nucleoprotein of influenza A virus. I. Characteristics and cross-reactivity of T-cell responses. Journal of Immunology 141, 3980-3987.

Van Embden, J. D. A., De Graaf, F. K., Schouls, L. M. \& Teppema, J. S. (1980). Cloning and expression of a deoxyribonucleic acid fragment that encodes for the adhesive antigen K99. Infection and Immunity 24, 1125-1133.

Wahdan, M. H., Serie, C., Cerisier, Y., Sallam, S. \& GERMANIER, R. (1982). A controlled field trial of live Salmonella typhi strain Ty21a oral vaccine against typhoid: three year results. Journal of Infectious Diseases 145, 292-295.

Weiss, A. A. \& Falkow, S. (1984). Genetic analysis of phase change in Bordetella pertussis. Infection and Immunity 43, 263-269.

Weiss, A. A. \& Hewlett, E. L. (1984). Virulence factors of Bordetella pertussis. Annual Review of Microbiology 40, 661-686.

Weiss, A. A., Hewlett, E. L., Myers, G. A. \& Falkow, S. (1983). Tn-5 induced mutations affecting virulence factors of Bordetella pertussis. Infection and Immunity 42, 33-41.

WinTHER, M. D. \& Dougan, G. (1984). The impact of new technologies on vaccine development. Biotechnology and Genetic Engineering Review 2, 1-39.

Winther, M. D., PickaRd, D. \& Dougan, G. (1985). A novel method for increasing bacterial cellular yields of a fimbrial subunit polypeptide. FEMS Microbiology Letters 28, 193-197.

Wraith, D. C., Vessey, A. E. \& AsKonas, B. A. (1987). Purified influenza virus nucleoprotein protects mice from lethal infection. Journal of General Virology 68, 433-440. 